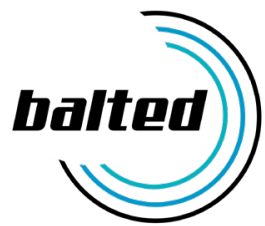

\author{
Balkanlarda Türk Dili ve Edebiyatı Araştırmaları \\ Studies on Turkish Language and Literature in the Balkans
}

Destanov, E. (2022). Doğu Makedonya Yörük Halk Kültüründe Hıdırellez Kutlama Geleneği. Balkanlarda Türk Dili ve Edebiyatı Araştırmaları, 4(1), 47-65. DOI: 10.47139/balted.1052170

\title{
Doğu Makedonya Yörük Halk Kültüründe Hıdırellez Kutlama Geleneği
} Celebration Tradition in Eastern Macedonian Nomadic Folk Culture

\section{Ekrem DESTANOV*}

\begin{abstract}
Öz
Türk dünyasının kültür değerlerinden biri olan "Hıdırellez" bahar mevsiminin gelişinde kutlanan bayramlarından biridir. Kış mevsiminin bitişini yazın ise başladığını ifade eden Hıdırellez her yılın altı Mayıs tarihinde kutlanmaktadır. Köklü bir geçmişe sahip olan Hıdırellez geleneği Türk kültüründe müstesna bir yer edinmiş olup Türk dünyasında asırlardır özel bir gün olma niteliğini korumaktadır. Bu makalenin konusuyla doğrudan bağlantılı olan Doğu Makedonya Yörük Halk Kültüründe de Hıdırellez geleneğine büyük önem verilmektedir. Ancak bu bölgedeki Hıdırellez geleneği ile ilgili müstakil ve ayrıntıI bilimsel çalışmalar yapılmış değildir. Bu nedenle söz konusu bölgede birtakım törenler eşliğinde kutlanan Hıdırellez geleneğinin bilimsel dünyadaki bilinirliğinin arttırılması amacıyla böyle bir çalışma ele alınmıştır. Söz konusu bölgeden konuya ilişkin halk bilimsel verilerin derlenmesinde folklor derleme çalışmalarında yaygın olarak kullanılan "gözlem", "görüşme" ve "mülakat" yöntemleri esas alınmıştır. Derleme çalışması sonrasında bu verilerin yedeklemeleri yapılmış olup yazıya aktarılmışlardır. Sonrasında ise söz konusu verilerin nitel araştırma yöntemindeki teknikler ile çözümlemeleri yapılmıştır. Konuyla ilgili verilerin incelenmesi ve çözümlenmesi sonucunda bölge halkının Hıdırellez bayramını genel anlamda usulüne uygun bir biçimde kutlanmasına büyük önem verdiği tespit edilmiştir.
\end{abstract}

Anahtar Kelimeler: Doğu Makedonya, Yörük, halk kültürü, Hıdırellez, kutlama.

\begin{abstract}
"Hidirellez", one of the cultural values of the Turkish world, is one of the holidays that celebrate the arrival of the spring season. Hidirellez, which expresses the and of the winter season and the beggining of the summer, is celebrated on the sixth of the May every year. Hidirellez tradition, which has a deep-rooted history, has gained an exceptionanl place in Turkish culture and has been a special day for centuries in the Turkish world. The Hidirellez tradition is also given great importance in the Eastern Macedonian Yuruk Folk Culture, which is directiy related to the subject of this article. However, on independet and detailed scientific studies have been conducted on the Hidirellez tradition in this region. For this reason, such a study has been discussed in order to increase the awareness of the Hidirellez tradition, which some ceremonies in the region in question, in the scientific world. The "observation", "interview" and "interview"
\end{abstract}

* Doktora Öğrencisi, İstanbul Üniversitesi, Türkiyat Araştırmaları Ana Bilim Dalı, İstanbul/TÜRKiYE, edestanov152@gmail.com, ORCID: 0000-0003-0699-6948 
methods, which are widely used in folklore compilation of folklore data on teh subject from the region in question. After the compilation study, these data were backed up and transcribed. Afterwards, the data in question were analyzed whith the techniques in the qualitative research method. As a result of the examination and analysis of the data on the subject, in has been determained that it is of great importance fort he people of the region to celebrate the Hidirellez holiday in general, in accordance with the rules.

Keywords: Eastern Macedonia, Yuruk, folk culture, Hıdırellez, celebration.

\section{Giriş}

Insanlık, tarihin eski çağlarından itibaren bazı olayları önemli olarak kabul etmiş ve onları törenlerle kutlama ihtiyacı içerisinde olmuştur. Bu olaylardan biri döngüsel bir yapıya sahip olan "tabiat" hadisesidir. Nitekim tabiatın geçiş dönemlerinden biri olan baharın çeşitli törenler eşliğinde kutlandığı ve bununla ilgili birbirinden farklı inanç ve uygulamaların yerine getirildiği görülmektedir.

Bahar mevsimine yönelik kutlamalar diğer kültürlerde olduğu gibi Türk kültüründe de mevcuttur. Türk kültüründe bahar mevsimini kutlama geleneği Hunlar dönemine kadar gitmektedir. Bu hususla ilgili Çin kaynaklarında önemli bilgiler yer almaktadır. Bu kaynaklarda Hunlar ve Göktürklerin senenin beşinci ayında coşkulu bir şeklide bayram törenleri düzenledikleri ve bu vesile ile kurban kestikleri, at yarışları düzenledikleri ve çeşitli şarkılar söyleyerek eğlendik- leri kaydedilmektedir (Ögel, 1971, s. 151-152). Hunlar ve Göktürklerin baharın gelişiyle ilgili gerçekleştirdikleri bu törenler, Türklerin Anadolu bölgesine yerleşmeleriyle birlikte bu coğrafyada da kutlanmaya başlamıştır (Sezen, 1995, s. 32). Söz konusu gelenek daha sonra i̇slam kültürüyle özdeşleştirilerek "Hıdırellez" adıyla anılmaya başlamıştır.

Köklü bir geçmişe sahip olan Hıdırellez kış mevsiminden yaz mevsimine geçişi, diğer bir ifadeyle tabiatın yeniden canlanışının coşkuyla kutlanmasını ifade etmektedir (Günay, 1993, s. 3). Bununla birlikte Hıdırellez güzellikler saçan, umut ve mutluluk veren bir gün olma özelliğine sahiptir. Aynı zamanda bugün hayırlı ve uğurlu kabul edilip bugünde dilenen tüm dileklerin gerçekleşeceğine olan inanış da hayli yaygındır (Sezen, 1995, s. 33).

Hıdırellez'in kutlandığı tarih takvimlere göre farklılık göstermektedir. Örneğin Rumi, diğer adıyla Jülyen takvimine göre Hıdırellez günü 23 Nisan'a denk gelmektedir (Uğurlu, 2015, s. 37). Günümüz Gregoryen takviminde ise 6 Mayıs tarihine düşmektedir. Bu bağlamda yıl, Takvimlere göre "Ruz-ı Hızır" ve "Ruz-ı Kasım" şeklinde iki bölüme ayrılmaktadır. 6 Mayıs'tan 8 Kasım'a kadar olan bu dönem 186 günden oluşup "Hızır Günleri", 9 Kasım ile 5 Mayıs arasındaki bu dönem ise 179 günden ibaret olup "Kasım Günleri” (Sezen, 1999, s. 82) olarak 


\section{ifade edilmektedir}

6 Mayıs ile 8 Kasım arasındaki günlerin "Hızır Günleri" şeklinde tanımlanmasının temelinde, "Hızır" ile "ilyâs" peygamberin 6 Mayıs tarihinde buluştukları inanışı yatmaktadır (Sezen, 1999, s. 82). Dolayısıyla Anadolu Türk-İslâm kültüründe söz konusu bahar bayramına "Hıdırellez" adının verilmesinin bu inanıştan ileri geldiği söylenebilir.

Asırlardır özel bir gün olma niteliğini koruyan Hıdırellez geleneği, Türklerin Anadolu'dan Balkan coğrafyasına yayılmalarıyla birlikte bu bölgede de kutlanmaya başlamıştır. İlgili coğrafyada da 6 Mayıs tarihinde kutlanan bu gelenek "Hıdırellez" adıyla tanımlanmaktadır. Bu kapsamda söz konusu gelenek, makalenin konusuyla bağlantılı olan Doğu Makedonya Yörük Halk Kültürü'nde de "Hıdrellez" olarak ifade edilmektedir.

Bahar bayramı bağlamında ele alınan bu çalışmada Doğu Makedonya Yörük Halk Kültürü'nde Hıdırellez kutlama geleneği incelenecektir. Konuyla ilgili yapılan ön araştırmalar sonucunda bu bölgedeki Hıdırellez bayramı ile ilgili bilimsel anlamda ayrıntılı çalışmaların yapılmadığı tespit edilmiştir. Bu sebeple söz konusu bölgede törenler eşliğinde kutlanan Hıdırellez bayramı geleneğinin bilimsel dünyada bilinirliğinin arttırılması amacıyla böyle bir çalışma gerçekleştirilmiştir. Ancak konunun irdelenmesine geçmeden önce ilgili bölge hakkında kısaca bilgi vermek yararlı olacaktır.

\section{Araştırmanın Gerçekleştirildiği Doğu Makedonya}

Coğrafi bir kavram olarak "Doğu Makedonya”, anlaşılacağı gibi Kuzey Makedonya'nın doğu kesimlerini kapsamaktadır. Kuzey Makedonya'daki Yörüklerin çoğu bu bölgede yaşamaktadır. Dolayısıyla literatürde bu alan "Doğu Makedonya", bölgede yaşamlarını sürdüren Yörükler ise "Doğu Makedonya Yörükleri” olarak tanımlanmaktadır.

Bu bölgedeki Yörükler Osmanlılar tarafından 14. yüzyılın sonlarına doğru yerleşme siyaseti olarak bu sahaya iskân ettirilmişlerdir (İnalcık vd., 1993, s. 14). Asırlardan beri bu bölgede varlıklarını sürdüren Yörükler sahip oldukları dil, din ve geleneksel yaşamlarında uyguladıkları örf, âdet, gelenek ve görenek gibi normları günümüze kadar taşıyabilmişler, diğer bir ifade ile koruyabilmişlerdir. Bu makalenin konusunu oluşturan "Hıdırellez" geleneği de muhafaza edilen gelenekler arasında yer almaktadır.

Yukarıda belirtilen tarihlerden Birinci ve Ikinci Dünya Savaşları'na kadar olan süreç içerisinde Kuzey Makedonya'nın doğu bölgesinde önemli sayıda 
Yörük köyleri yer almaktaydı. Ancak söz konusu savaşlar sonrasında gerçekle- şen göçler ile birlikte bu köylerin birçoğu terkedilmiştir (Oktay, 2018, s. 1472). Söz konusu bölge Yörük yerleşim yerlerinden olsa gerek Sırp ve Hırvat kaynak- larında "Makedonya Yörüklüğü" olarak geçmektedir (ibrahimsoylu, 2021, s. 228-229). Dolayısıyla bu alan her ne kadar Doğu Makedonya Yörük yerleşimleri adıyla anılsa da kaynaklarda "Makedonya Yörüklüğü" olarak geçmesi nedeniyle bölge Yörüklerini tam manasıyla ifade etmesi açısından "Makedonya Yörüklüğü" kullanımının daha isabetli olacağı kanaati hâsıl olmaktadır. Makaleye "Doğu Makedonya Yörük Halk Kültüründe Hıdırellez Kutlama Geleneği" adının verilmesinin sebebi ise bölgenin genel itibariyle "Doğu Makedonya" olarak tanımlanması dolayısıyladır.

\section{Hıdırellez Bayramı Geleneği}

"Hıdırellez", Asya kıtasına uzanan ve Türk kültürüne dayanan mevsimlik bayramlarından biridir. ${ }^{1}$ Söz konusu bahar bayramı, İslâmiyet sonrasında İslâm kültürüyle özdeşleştirilerek "Hıdırellez" adıyla anılmaya başlamıştır. Bu bayramın İslâmlık etkisinde "Hıdrellez" olarak tanımlanmasının temelinde, "Hızıı" ile "ilyâs" peygamberle ilgili inanış yatmaktadır. İnanışa göre "Hızır" ile "ilyâs" peygamber, yılın belli bir tarihinde görüşmektedirler. Bu tarih ise bahar bayramın kutlandığı 6 Mayıs'a denk gelmektedir (İslâm Ansiklopedisi: Hıdrellez, 1987).

Dolayısıyla ilgili bayramın "Hıdrellez" adını buradan aldığını söylemek mümkündür. Nitekim Hıdırellez kelimesinin hangi anlamı ihtiva ettiği ve niçin kutlandığı hususundaki rivayetlerden biri, Hızır ile illyâs peygamberin 6 Mayıs'ta yeryüzünde buluştuklarına ve onlarla birlikte sevinen kimselerin dileklerinin gerçekleşeceğine olan inanışla ilgilidir (Günay, 1993, s. 3).

Yukarıda belirtilen dönemlerden günümüze kadar gelen "Hıdrellez" bayramı hakkında birtakım çalışmalar yapılmıştır. Bu çalışmalardan bazıları söz konusu bahar bayramının ana karakteri olan Hızır'a ait hikâyenin kökeniyle ilgilidir. İlgili çalışmalarda Hızır hikâyesiyle eski efsanelerden olan "Gılgamış Destanı", "iskender Hikâyesi", "Yahudi Efsanesi", "Glaukos Hikâyesi" ve Kur'an'da yer alan "Hz. Musa" ile "Hızır" kıssası arasındaki benzerlikler ele alınmıştır (Yüce, 2011, s. 251). Bu çalışmalardan hareketle Hıdrellez bahar bayramının kökeninin eski çağlara uzandığı ifade edilebilir.

1 Türk toplulukları arasında asırlardan beri "Nevruz" da Hıdrellez gibi bir bahar bayramı olarak kutlanmaktadır. Nevruz hakkında geniş bilgi için bk., (İslâm Ansiklopedisi: Nevruz, 2007); (Şengül, 2008, s. 61-73). 


\section{Doğu Makedonya Yörük Kültüründe Hıdırellez Kutlama Geleneği}

"Hıdrellez", Türk toplulukları arasında kutlanan bahar bayramlarından biridir. Resmî ve dinî bayramlardan olmamasına rağmen Hıdrellez, asırlardır özel bir gün olma niteliğini korumaktadır (Günay, 1993, s. 3). Hıdrellez, diğer Türk topluluklarında olduğu gibi Balkan Türk toplulukları arasında da yaz mevsiminin başlangıcı olarak kabul edilmekte ve 6 Mayıs tarihinde kutlanmaktadır. Bu husus, makalenin konusuyla ilgili olan Doğu Makedonya Yörük Halk Kültür için de geçerlidir. Nitekim bölge Yörük kültüründe de Hıdrellez yazın başlangıcı kabul edilmekte ve aynı tarihte kutlanmaktadır. ${ }^{2}$

Hıdrellez kavramı, yaygın görüşe göre "Hızır" ile "ilyâs" isimlerinin halk dilinde birlikte telaffuz edilişlerinden oluşmaktadır (Günay, 1993, s. 3). Halk arasında peygamber kabul edilen ve Hızır Aleyhisselâm olarak adlandırılan Hızır'ın zor durumda kalanlara yardım ettiğine inanılmaktadır. Ayrıca onun "âb-ı hayat", yani ölümsüzlük suyundan içmiş olması sebebiyle ölümsüz olduğuna, kimliğini gizleyerek insanların arasına karıştığına ve sevdiklerine iyilik ettiğine olan inanış da hayli yaygındır (Sezen, 1995, s. 32). Ilyâs ise Kuran-ı Kerim'de adı geçen peygamberlerden biri olup denizlerde mahsur kalan kimselere yardım elini uzattığına inanılmaktadır (İslâm Ansiklopedisi: Hıdrellez, 1987).

Bu bağlamda, çalışmanın yürütüldüğü bölgede de "Hıdrellez" kavramının aynı adlardan oluştuğu belirlenmiştir. Ancak kavramın bölge ağız özelliklerinden dolayı birtakım farklııklar arz ettiği tespit edilmiştir. Örneğin Ustrumca şehrine bağlı Yüksek Mahalle Köyünde "Idırlez", (KK 3, 4) Radoviş şehrine bağlı Kılauzlu, Alikoç ve yakınlarında yer alan Kocalı, Pırnallı köylerinde ve iş̧tip şehrine bağıı Radanya, Ojalı köylerinde "Idırellez", (KK 2, 7, 10) olarak ifade edilmektedir. Yine Radoviş'e bağlı Konçe ve Topolnitsa Köylerinde ise "Edırlez" (KK 1, 11) şeklinde tanımlanmaktadır. ${ }^{3}$

Bölgenin yerel ağızlarında her ne kadar farklı ses özellikleriyle ifade edilse de Hıdırellez kavramının anlam bütünlüğünü koruduğu anlaşılmaktadır. ${ }^{4}$ Bu böl-

\footnotetext{
2 Hıdrellez, araştırmanın gerçekleştirildiği bölgede yaşayan Hıristiyanlar için de önemli bir gün sayılmaktadır. Hıristiyanlık kültüründe "Gürgüvden/Ѓурѓувден" şeklinde ifade edilen 6 Mayıs gününün Saint Georges'a dayandırıldığından ileri geldiği söylenebilir. Ayrıntılı bilgi için bk. (Döğüş, 2015, s. 77).

3 Kuzey Makedonya'nın diğer bölgelerinde yaşayan Türk toplulukları arasında "Hıdrellez" kavramının ifade edilişi hakkında bk., (Çalışkan, 2015, s. 382).

4 Çalışmanın yürütüldüğü Doğu Makedonya bölgesinde "Hıdrellez" kavramının oluşumu hususunda iki efsane anlatılmaktadır. Birinci efsane Hızır ile illyâs peygamberin 6 Mayıs tarihinde buluşmalarıyla ilgili, ikincisi ise "Hıdır" ile "Ellez"in, diğer bir ifadeyle genç bir kız ile erkeğin arasındaki büyük sevgiye ilişkindir. Efsaneye göre bu genç kız ile erkeğin görüşmeleri sınırlıymış. Yılda yalnız bir kere 6 Mayıs tarihinde yeşil alanlarda görüşürlermiş. İnsanlar ilgili tarihte yeşillik alanlara çıkıp eğlenerek bir anlamda bu genç kız ile erkeğin sevgisine saygı göstermektedirler (Ago, 1982, s. 7).
} 
gede Hıdırellez'in neden kaldığına yönelik inanış, yukarıda ifade edilen inanışa benzerlik göstermektedir (KK 9).

Bununla beraber, Hızır ile ilgili başka inanışlar da mevcuttur. Örneğin İslâm inanışına göre Hızır ermiş biri olarak kabul edilip Allah tarafından Müslümanlığı korumakla görevlendirilmiştir. Medeniyet tarihi açısından önemli bir yere sahip olan Kudüs şehrinde yaşamını sürdürmekte ve dilediği zaman dilediği yerde görülebilmektedir. Çoğu kez birlikte anıldığı illyâs peygamberin kardeşidir de aynı zamanda (Sezen, 1995, s. 32).

\subsection{Hıdırellez'e Yönelik Yapılan Hazırlıklar}

Bahar bayramı olarak "Hıdrellez" Türk dünyasının ortak kültür değerlerinden biridir. Yılda bir kez kutlanan bu değerin tam anlamıyla yerine getirilebil- mesi için birtakım ön hazırlıklar yapılmaktadır. Eski çağlarda, Hun ve Göktürk gibi eski Türk devletlerinde bahar bayramıyla ilgili hazırlıklar genellikle hakanlar tarafından yaptırılırdı. Ancak bu husus zamanla değişime uğramıştır. Nitekim gü- nümüz Türk dünyasında bahar bayramına yönelik yapılan hazırlıkların daha çok bireysel bir durum sergilediği bilinmektedir (Kahraman-Arıkan, 2015, s 18).

Makalenin konusuyla doğrudan bağlantılı olan Doğu Makedonya Yörük halk kültüründe de Hıdrellez bayramına yönelik birtakım hazırlıklar yapılmaktadır. Bu sahada Hıdrellez ile ilgili yapılan hazırlıklar bireysel olarak gerçekleştirilmekte- dir. Söz konusu bölgede bu hazırlıklar Hıdrellez öncesinden başlamaktadır. Hazırlıkların birkaç gün öncesinden başlaması dinî bir bayram olmamasına rağmen bölge kültüründe Hıdrellez bayramının ne kadar önemli bir yere sahip olduğunu göstermektedir.

Illgili sahada Hıdrellez hazırlıkları temizlik işleriyle başlamaktadır.

Hıdırellez'den bir gün önce, diğer bir ifadeyle Hıdrellez arifesinde genç kızlar ev temizlik işlerini yapmaktadırlar: Odaları süpürüp kapı ve pencereleri silerler, akabinde avluları ve evlerin çevrelerini süpürürler. Daha sonra ise eşya yıkama işlerini gerçekleştirirler (KK 3,7). Hıdırellez'in öncesinde bu tür temizlik işlerinin yapılmasının, Hıdırellez'e temiz bir şekilde girilmesinin bilinçaltında Hızır'ın te- miz yerlere geldiği inanışının yer aldığını söylemek müınkündür.

Temizlik işleri devam ederken bir yandan ev hanımları ezilmiş ceviz karışımından oluşan "yufka", "ölçü" vb. baklava türlerinin yanı sıra "kapama", "kuru fasulye", bahçeden toplanmış taze yeşil labada otundan yapılan "kaşa" ${ }^{6}$ ve "çorba" gibi farklı yemekler çeşitleri hazırlarlar (KK 4). Hazırlanan yemekler arasında

5 İlgili inanış hakkında geniş bilgi için bk., (Günay, 1993, s. 3). 6 Bir çeşit unlu mamul yemeği. 
kaşa yemeği ayrı bir öneme sahiptir. Zira bölge halkının inanışına göre Hıdırellez sabahı kaşa yemeğinden yenilmesi hâlinde sene boyunca hastalık, uğursuzluk ve tembellik gibi olumsuzlukların önüne geçişmiş olunmaktadır (KK 9). Bu se- beple kaşa yemeğinden yenilmesine büyük önem verilmektedir.

Söz konusu sahada Hıdrellez bayramına dönük yapılan hazırlıklardan biri de uğursuzluk ile ilgilidir. Güneş batımı öncesinde çocuklar veya ebeveynler sütleğen ve söğüt dalları gibi yeşillikler toplayıp evlerin giriş kapılarına veya kapı başlarına, kümeslerin, ağılların vb. yerlerin kapılarına koymaktadırlar (KK 3, 7). Bu hazırlıklar tamamlandıktan sonra "martıfal" adı verilen ve erguvan, gonca vb. çiçeklerden oluşturulan küçük demetleri çömlek veya küp içine koyma işlemi gerçekleştirilmektedir.

\subsection{Martıfal Âdeti}

Türk dünyasında Hıdrellez bayramı öncesinde gerçekleştirilen işlemlerden biri de baht, kısmet açma veya bir çeşit fal bakma olarak tanımlanabilen ve "martıfal" adı verilen âdet ya da uygulamadır (Günay, 1993, s. 3). Türk toplulukları arasındaki uygulanışında bazı farklılıkların olduğunu ifade eden Umay Gü- nay "martıfal" âdetinin nasıl yerine getirildiğini şu şekilde açıklamaktadır:

"5 Mayıs günü, öğleden sonra, büyük bir çömlek genç kızlar tarafından kapı kapı dolaştırılır. Geleceğe yönelik niyet tutmak, talih ve kısmet açtırmak isteyen genç kız ve kadınlar, yüzük küpe gibi eşyalarını çömleğin içine atarlar. Çömlek ağzına kadar temiz su ile doldurulur. Ağzı beyaz tülbentle bağlanan çömlek bir gül fidanının dibine yerleştirilir. Hızır Aleyhisselam'ın çömleğin durduğu fidanın altına uğrayacağına ve herkesin dilediğini yerine getireceğine inanılır. Hıdrellez sabahı erkenden çömlek gül fidanının altından alınır. Yeşillik bir yerde bazen bir evde genç kızlar ve hanımlar çömleğin etrafında toplanırlar. Hızır Aleyhisselam'a dualarla çömlek açılır. Çömleğin içine bakmadan, önceden konulan eşyalar çıkarılırken iyi mâni söyleyen ve çok mâni bilen bir hanım da mâni okur. Çömlekten çıkan eşya kiminse, söylenen mâninin o kişinin talihini ifade ettiğine inanııı ve mâni bu hâle göre yorumlanır. Bu tören sonrasında okunan mânilere niyet mânileri adı verilir" (Günay, 1993, s. 3).

Umay Günay'ın "Ritüeller ve Hıdrellez" adlı çalışmasında bahsettiği "martıfal" âdeti, makale konusuyla ilgili çalışmaların gerçekleştirildiği Doğu Makedonya Yörük halk kültüründe de mevcuttur. Söz konusu halk kültüründe uygulanan "martıfal" âdeti, Günay'ın yukarıda yer verilen açıklamasına benzerlik arz etmektedir.

İlgili bölgede "martıfal" âdetinden bahsetmeden önce "martıfal" kavramı- 
nın bölgede ifade ediliş biçiminden kısaca söz etmek yerinde olacaktır. Yörenin ağız özelliklerinden olsa gerek "Hıdrellez" gibi "martıfal" kavramı da bölgeden bölgeye farklılık göstermektedir. Örneğin İştip şehrine bağlı Radanya köyünde literatürde yer aldığı şekliyle "martıfal" (KK 6), Ustrumca şehrine bağlı Yüksek Mahalle köyünde "mantufar", (KK 4) Radoviş şehrine bağlı Topolnitsa köyünde ise "mane" (KK 11) (mâni) olarak ifade edilmektedir. Araştırma kap- samı dışında kalan bölgelerde "martıfal" kavramının farklı ifade ediliş biçimleri mevcuttur. Örneğin Ohri Türkleri arasında bu kavram "martufal" şeklinde dillendirilmektedir (Ago, 1982, s. 8). Martıfal âdetinin "mâne" şeklinde dillendirilmesinin bu âdetinin mâni söylenerek yerine getirilmesinden kaynaklandığını söylemek mümkündür.

Farklı kelimelerle ifade edilen "martıfal" âdeti Doğu Makedonya yöresinde tüm temizlik işleri bitirildikten sonra, gün batımına yakın zaman diliminde gerçekleştirilmektedir. Genç kızlar, su doldurulmuş çömlek, küp vb. su kabına konulmak üzere aile fertlerinin her biri için erguvan, gonca ve benzer çiçeklerden oluşan küçük demetler hazırlarlar. Bu demetlerin kime ait olduğunu belli etmek içinse yüzük, küpe, kolye gibi takılardan nişan koyarlar. Akabinde genç kızların hepsi, bu demetleri su kabının içine atmak üzere "martıfal" âdetinin gerçekleştirildiği alanda bir araya gelirler. Sonra ise çeşitli mâniler söyleyerek ve dilekler dilenerek hazırlamış oldukları demetleri su doldurulmuş çömlek veya küpe atarlar. Demetleri su kabının içine atma işlemi bittikten sonra su kabının ağzını "al" (kırmızı) renkli bir tülbent ile kapatırlar. Sonrasında bu su kabını bir gül ağacının dibine koyup ertesi sabaha çıkarana kadar bekletirler (KK 3, 10, 11).

Genç kızlar tarafından hazırlanan küçük demetlerin içine atıldığı çömlek veya küpün gece boyunca gül ağacının altında bekletilmesi, diğer Türk toplulukları arasında olduğu gibi Hızır'ın söz konusu gül ağacının altına gelip tüm dileklerin yerine getireceğine olan inanıştan ileri geldiği söylenebilir (Günay, 1993, s. 3). Demetlerin içine konulduğu çömlek ya da küpün suyla doldurulması ise Türk mitolojisindeki "su" kültünü yansıtmaktadır. ${ }^{7}$

\subsection{Hıdırellez Sabahına Yönelik İşlemler}

Hıdırellez, dinî veya millî bayram niteliği taşımasa da Türk dünyasında önemli bir yere sahiptir. Hıdırellez'in asırlardır etkin bir biçimde kutlanması bu öneme sahip olduğunu açıkça göstermektedir. Türk dünyasının bir parçası olan Doğu Makedonya Yörük Halk Kültürü'nde Hıdırellez bayramına hatırı sayılır bir

7 Suyun içinde mevcut olan gücün farklı biçimlerde belirdiğinden ve göl ile su kaynakları ve nehirlerde, Türk kültüründe ise "kutsanmış sular"da yaşadığı ifade edilmektedir. "Su" kültüyle ilgili ayrıntılı bilgi için bk., (Roux, 2011, s. 115-116). 
önem atfedilmektedir. Dinî bayramlardan olan Ramazan ve Kurban bayramlarında olduğu gibi Hıdırellez sabahı güneş doğmadan önce uykudan uyanmaya özen gösterilir. Küçük büyük fark etmeksizin yeşillik alanlara, yerel tabirle çayırlara gidilip yeşilliklerde dolaşılı yuvarlanılmaktadır. Bölge halkı arasında uygulamaya "yeşilini almak, yeşillenmek" denilmektedir (KK 9).

Hıdırellez sabahı yeşillik alanlarda bulunulmasının, Hızır'ın Hıdırellez sabahı yeryüzüne uğrayıp sıkıntıda olanlara yardım edeceğine ve dilenilen tüm dilekleri yerine getireceğine olan inanıştan ileri geldiği bilinmektedir (Günay, 1993, s. 3). Dolayısıyla yöre ağzında yer alan "yeşilini almak" ifadesi, Hızır'ın yeryüzünde dağıtacağı iyilik ve güzelliklerden kapmak şeklinde yorumlanabilir.

Araştırmanın gerçekleştirildiği bölgede Hıdırellez sabahı keçi, koyun ve sığır sürülerinin de yeşillik alanlara götürülüp otlatıldığı görülmektedir. Büyük ve küçükbaş hayvanların Hıdırellez sabahı yeşillik yerlerde otlatılması, Hıdırellez günü cansız varlıklarla canlı varlıkların yeni bir hayata kavuşacakları inanışından kaynaklandığı söylenebilir (Günay, 1993, s. 3).

Söz konusu bölgede Hıdırellez sabahı yerine getirilen uygulamalardan biri de "berekete" yönelik işlemdir. Hıdırellez sabahı köy halkı güz mevsiminde ektikleri ekinleri dolaşmaya giderler. ${ }^{8}$ Başak bağlamış ekinlerin başaklarından koparıp tahılların depolandığı yere (ambar) koyarlar. Bölge halkı arasında bu uygulama "bereketi" simgelemektedir. Hıdırellez sabahı yukarıda sözü edilen uygulamalardan sonra, Hıdırellez öncesinde çeşitli dilek ve isteklere yönelik hazırlanan çiçek ve yeşillik demetlerinin çömlek veya küpten çıkarılması, diğer bir ifade ile "martıfal" âdeti yerine getirilmektedir.

\subsubsection{Martıfal Çıkarma Âdeti}

"Martıfal" âdeti, yukarıda ifade edildiği gibi baht, kısmet açma veya bir çeşit fal bakma şeklinde tanımlanan âdetin adıdır (Günay, 1993, s. 3). Martıfal Hıdırellez bahar bayramında uygulanan belki de en önemli âdettir. Bu âdet ma- kalenin konusuyla bağlantılı olan Doğu Makedonya Yörük Halk Kültürü’nde de büyük öneme sahiptir.

"Martıfal" âdeti diğer Türk toplulukları arasında olduğu gibi söz konusu bölge de hem Hıdırellez öncesinde hem de Hıdırellez günü uygulanmaktadır. Bu bölgede Hıdırellez öncesinde gerçekleştirilen âdete "mantufar, martıfal ya da mane koyma" (KK 3,11), Hıdırellez günü uygulanana ise "mantufar, martıfal ya da mane çıkarma" $($ KK 3, 11) adı verilmektedir.

8 Hıdırellez sabahı ekinlerin dolaşılması geleneği Bulgaristan Türkleri arasında da mevcuttur, bk., (Özkan, 2002, s. 17). 
Çalışmanın odaklandığı bölgede "martıfal çıkarma" âdeti, köylerin belli merkezî yerlerinde gerçekleştirilmektedir. Hıdırellez sabahı genç kızlar toplanıp önceki günün akşamında küpü bıraktıkları gül ağacının dibinden alıp söz konusu âdetin uygulandığı alana götürürler. İçlerinden bir kızın başına "al" (kırmızı) renkli bir tülbent bağlayıp eline bir ayna vererek küpün yanına oturturlar. ${ }^{9}$ Sonra kol kola geçip mâni söylemeye başlarlar. Her mâninin bitişinde küpün yanına oturtulan genç kız küpten bir demet çıkarır. Bölgede bu âdete "martıfal" çıkarma denilmesinin bu uygulamadan geldiği söylenebilir. Küpten çıkarılan demetin kime ait olduğu takılan yüzük, küpe vb. nişanlardan anlaşılır ve bu mâni o kişiye ithaf edilir. Küpün içindeki demetler bitinceye kadar "martıfal çıkarma" âdeti devam eder. Yüzük, küpe vb. eşyaların yanı sıra küçük demetlerin içine atıldığı küpün ağzının kapatılmasında ve bu eşya ve demetlerin çıkarılması esnasında kullanılan "al" renkli tülbent, Türk kültüründe "dişiliği" simgelemektedir (Ekici, 2016, s. 104). Demetler küpten çıkarılırken söylenen mânilerin ise aynı zamanda demet sahiplerinin bahtını ifade ettiğine inanılmaktadır. Martıfal âdetiyle ilgili buna benzer inanışların diğer Türk toplulukları arasında da olduğu görülmektedir. ${ }^{20}$ Martıfal çıkarma işleminde kullanılan ayna ${ }^{11}$ ise Türk mitolojisinde Umay Ana'nın kutsalığını ve yeryüzüne kuş şeklinde inişini simgelemektedir (Ergun, 2010, s. 279).

Yerel tabirle "mantufar/mane çıkarma" işlemi esnasında söylenen mânilerden bazıları şöyledir:

Anterim ${ }^{12}$ kumaş olsun

Üstüne kuşlar konsun

Ver anne istediğme

İsterse berduş olsun (KK 3)

\footnotetext{
9 Türk dünyasının bazı bölgelerinde "martıfal" âdeti uygulamasında yüzük, küpe, bileklik gibi eşyaların içine konulduğu çömlek veya küpün ağzının Hızır Aleyhisselam'a dua edilerek açıldığı görülmektedir. Bk., (Günay, 1993, s. 3).

20 Bk., (Günay, 1993, s. 3).

11 Farsça kökenli bir kelime olan ayna; karşısındaki şekli ve renkleri aksettiren madenî levha veya arkası sırlı düz cam olan süslenme eşyası şeklinde tanımlanmaktadır. İnsanların kendi yüzlerini görme ve süslenmelerini sağlama gibi temel işlevinin yanı sıra ayna, âdet olarak da kullanılmaktadır. Araştırma bölgesinde martıfal çıkarma işleminde yer alan aynanın âdet olarak kullanıldığı görülmektedir.
}

12 Gömlek. 
Hisardan indim düze

Su koy verdim Mergüze

Yedi yıl hizmet ettim

Ela gözlü güzele (KK 3)

Bir taş attım kilseye

Mavi püskül enseye

Ben askere giderim

Gönül verme kimseye (KK 5)

Çakmağımı çakayım

Sigaramı yakayım

Gönder yârim resmini

Özledikçe bakayım (KK 5)

Kiremitte gezerim

Badem şeker ezerim

Komşu kızı dururken

Niye bekâr gezeyim (KK 5)

Bi hoca gelir hoca

Elinde sarı bohça

Bana küçük demeyin

Ben de ararım koca (KK 5) 
Denizde kara balık

Yüreğim sana yanık

Bu akşam kaçmayayım

Sokaklar kalabalık (KK 8)

Sıra sıra kazanlar

Kara yazı yazanlar

Evlat yüzü görmesin

Aramızı bozanlar (KK 8)

Gidin bulutlar gidin

Yârime selam edin

Eğer yârim uyursa

Yüzüne gölge edin (KK 5)

Ak koyun meler misin

Mor menekşe yer misin

Sevdiğini almadan

Ben evlendim der misin (KK 8)

Çık çeşmeye göreyim

Eline gül vereyim

Senin gibi güzeli

Nasıl ele vereyim (KK 8) 
Güle bindim gülmedim

Gülden indim ölmedim

Kara gözlü yârimi

Üç ay oldu görmedim (KK 5)

Yılana bak yılana

Yılan gider ormana

Ninem beni verecek

Kara gözlü oğlana (KK 5)

Koz kökü bıtrak bıtrak

Sen çiçek ol ben yaprak

Gel sarılalım yârim

Düşman gözüne toprak (KK 5)

Bunar yolu bu mudur

Kova doli su mudur

Yüksek Male ${ }^{13}$ içinde

Benim yârim bu mudur (KK 8)

Motor aldım yârim

Suya salalım yârim

İkimiz de bir boyda

Nişan olalım yârim (KK 8)

13 Araştırma bölgesinde yer alan bir Yörük köyü. 
Karanfilim top beyaz

Ayrı düştük biz bu yaz

Eğer beni seversen

Mektubunu sıkça yaz (KK 8)

Martıfal âdetinin uygulandığı sırasında söylenen mâniler konuları bakımından incelendiğinde "sevda", "gurbet", "mektup" ve "askerlik" gibi çeşitli konularla ilgili oldukları görülmektedir. Ancak çoğunun "sevda" konusuna yönelik oldukları öne çıkmaktadır. Söz konusu mâniler hece ölçüsü bağlamında ele alınacak olursa, hece ölçüsünün "yedili" kalıbıyla söylendiği anlaşılmaktadır. Söylenen bu mânilerin kafiye şeması ise "aaba" şeklindedir.

\subsubsection{Hıdırellez Kutlamaları}

Kış mevsiminin bitişini yazın ise başladığını ifade eden bahar bayramı, diğer bir ifade ile Hıdırellez yüzyıllardan beri kutlanmaktadır. Söz konusu bahar bayramı Türk dünyasında çeşitli törenler eşliğinde gerçekleştirilmektedir. Bu bağlam- da Hıdırellez bayramı Doğu Makedonya Yörük Halk Kültürü'nde de coşkulu bir şekilde kutlanmaktadır.

Araştırmanın odaklandığı bölgede Hıdırellez sabahı "martıfal" âdetinden sonra kahvaltı edilir. Kahvaltıda Hıdırellez'e özel hazırlanmış yemekler yer alır. Daha sonra yeni kıyafetler giyilerek Hıdırellez günü kutlanır (KK 3, 7, 11).

Doğu Makedonya yöresinde Hıdırellez kutlamaları diğer Türk topluluklarında (Günay, 1993, s. 3) olduğu gibi daha çok gençler tarafından gerçekleştirilmektedir. Genç kız ver erkekler Hıdırellez kutlamalarının yapıldığı köy merkezlerine giderler. Kimi gençler kasetçalardan çeşitli müzik parçaları açıp halay çekerken, kimileri ise meydandaki ağaca salıncak kurup mâni eşliğinde sallanmaktadırlar. Hıdırellez kutlamaları gün sonuna kadar bu minval üzere devam etmektedir. Yaş itibarı ile daha büyük olan kimseler arasında ise ziyaretleşmeler yapılır. Bu anlamda Hıdırellez, bir bahar bayramı olmasının yanında sosyalleşme günüdür de aynı zamanda.

Bu bağlamda, Valandova şehrine bağlı Çalıklı köyünde "Uluslararası Hıdrellez Bahar Şenlikleri Festivali” düzenlenmektedir. Festivale, Kuzey Makedon- ya devlet temsilcilerinin yanı sıra Kuzey Makedonya'nın farklı bölgelerinden TürklerYörükler, Türkiye Cumhuriyeti Kültür Bakanlığı tarafından temsilciler ve Bulgaristan gibi komşu ülkelerde yaşayan Türkler katılmaktadır. Söz konusu festivalde çeşitli halk oyunları oynanarak birbirinden farklı gösteriler sergilenmektedir. Bununla birlikte yağlı güreş müsabakaları da festival kapsamında düzenlenmektedir. Özetle Hıdırellez bayramı Doğu Makedonya Yörükleri arasında 
coşku ile kutlanmaktadır.

\subsection{Hıdırellez ile IIIgili Halk Innanışları}

Halk inanışları; "halk arasında yaşayan, geçmişten günümüze taşınan ve herhangi bir müesses dine ait olmayan inançların bütünü" (Eroğlu, 2006, s. 87) "tamamen din olmayan ve dinin tamamen dışında kalmayan kültürel unsurlar" (Kalafat, 1999, s. 88) gibi anlamlara gelmektedir. Halk inançları, en yalın hâliyle toplumların inanç gereksinimlerini besleyen kültürel değerler olarak açıklanabi- lir.

İnanç bağlamında Doğu Makedonya Yörük Halk Kültüründe birçok halk inanışının yaşadığı tespit edilmiştir. Bu inanışların bir kısmı Hıdırellez ile ilgilidir. Hıdırellez'e yönelik halk inanışların bazıları aşağıdaki gibidir:

Doğu Makedonya yöresinde Hıdırellez'in öncekisi akşam ev, kümes, ağıl vb. yerlerin kapılarına sütleğen otu konulmaktadır, zira sütleğen otunun gelebilecek tüm kötülük ya da uğursuzluklara karşı koruyup uğur getireceğine inanılmaktadır (KK 4). Ayrıca ısırgan otuyla söğüt ve sarmaşık dalları toplanıp, ısırgan otuyla söğüt dalları aynı amaçla yukarıda sözü edilen mekânların kapı başlarına asılırken, sarmaşık dalları ise Hıdırellez sabahı bele takılıp köy çeşmesine gidilerek her türlü ağrı veya hastalığın gitmesi ve sene boyunca sağlıklı olunması amacıy- la akan suya atılmaktadır. Bununla beraber, Hıdırellez sabahı güneş doğmadan önce uykudan uyanılması hâlinde sene boyunca uykudan uyanmanın zor gelmeyeceğine, işlerin iyi gideceğine, herhangi bir uğursuzluğun gelmeyeceğine, uyanılmaması durumunda ise uğursuzluğun eksik olmayacağına inanılmaktadır (KK 9). Dolayısıyla Hıdırellez sabahı güneş doğmadan önce uykudan uyanmaya dikkat edilmektedir. Bu bölgede, Hıdırellez sabahı uğursuzluğun gitmesi amacıyla yeşil çimenlere uzanıp yuvarlanılması, yeşil yaprakların ele yüze sürülmesi gibi uygulamalar da söz konusudur. Bu uygulamaların yerine getirilmesi hâlinde önceye kıyasen daha sağlıklı, dinç, diğer bir ifade ile uğurlu olunacağına; aksi takdirde uğursuzluğun geleceğine inanılmaktadır (KK 7).

Araştırmanın konusunu oluşturan bölgede davar ve sığırların da üzerlerine herhangi bir uğursuzluğun gelmemesi amacıyla birtakım uygulamaların yerine getirildiği tespit edilmiştir. Davar ve sığırlar Hıdırellez sabahı güneş doğmadan önce otlatılmaya götürülüp, güneşin doğuşu sonrasında eve getirilirken yeni yapraklanmış meşe, söğüt vb. ağaç dallarıyla hafifçe vurulur ki sağlıklı olsunlar, üzerlerine bir uğursuzluk gelmesin. Diğer bir uygulama ise, "martifal" âdetiyle ilgili olarak kullanılan sudan davar ve sığırların üzerlerine saçılmasıdır. Zira bu 
suyun davar ve sığırların üzerlerine gelebilecek kötülüğü veya uğursuzluğu en- gelleyeceğine inanılmaktadır (KK 3, 4).

\section{Sonuç}

"Hıdırellez", Hunlar dönemine kadar giden bahar bayramlarından biridir.

Söz konusu bahar bayramı, Türklerin İslâmiyet’i kabul etmeleriyle İslâm kültürü ile özdeşleştirilerek "Hıdırellez" adıyla anılmaya başlamıştır. Bu bayramın "Hıd- rellez" olarak tanımlanması, "Hızır" ile "ilyâs" peygamberle ilgili inanıştan ileri gelmektedir. Halk arasında hâlâ yaşayan bu inanışa göre "Hızır" ile "ilyâs" pey- gamber yılda bir kez görüşmektedirler. Onların görüştükleri bu tarih ise bahar bayramın kutlandığı 6 Mayıs'a denk gelmektedir. Dolayısıyla bahar bayramının "Hıdırellez" adını buradan aldığını ve o dönemlerden günümüze "Hıdırellez" adıyla geldiğini söylemek mümkündür.

Türk dünyasında önemli bir yere sahip Hıdırellez bahar bayramı kış mevsiminin bitişini yazın ise başladığını, diğer bir ifade ile tabiatın canlanışını ifade etmekte olup 6 Mayıs tarihinde kutlanmaktadır. Bu husus Türk dünyasının bir parçası olan Doğu Makedonya Yörük Halk Kültürü için de geçerlidir. Söz konusu bahar bayramı ilgili bölge kültüründe de yazın başlangıcı kabul edilmekte ve aynı tarihte kutlanmaktadır. Anadolu Türk-İslâm kültüründe olduğu gibi bu böl- ge de "Hıdırellez" kavramının "Hızır" ile "ilyâs" isimlerinin birleşiminden oluştu- ğu tespit edilmiştir.

Çalışmanın konusuyla doğrudan bağlantılı olan Doğu Makedonya Yörük Halk Kültürü’nde Hıdırellez bayramına büyük önem verildiği belirlenmiştir. Hıdırellez için önceden yapılan hazırlıklar ile eski Türk âdetlerinden olan "martıfal" ve "yeşillenme" gibi âdetlerin hâlâ uygulanıyor olması bunu açıkça göstermektedir.

Söz konusu bölgede yeşillik kavramı ön plana çıkmaktadır. Hıdırellez sabahı yeşil alanlara uzanılıp yuvarlanılması, el ve yüze yeşil yaprakların sürülmesi yanında yeşilliğin öne çıkması, Hızır’ın Hıdırellez sabahı yeşillik yerlere uğrayacağına, sıkıntıda olanlara yardım edeceğine ve dilenilen tüm dilekleri yerine getireceğine olan inanıştan ileri geldiğini söylemek mümkündür.

Çalışma ile birlikte Doğu Makedonya Yörük Halk Kültüründe Hıdırellez bayramının coşkulu bir şekilde kutlandığı sonucuna varılmıştır. 


\section{Kaynakça}

Ago, A. (1982). Ohri, Radoviş ve Iştip ilç̧elerinde Yaşayan Türk Halkının Hıdrellez Âdet ile Mânileri. II. Milletlerarası Türk Folklor Kongresi Bildirileri. (Cilt 2). Ankara: Kültür ve Turizm Bakanlığı Millî Folklor Araştırma Dairesi, 5-18.

Çalışkan, Ş. (2015). Türklerde Hıdrellez İnancı: Makedonya Örneği. International Journal of Science Culture and Sport, 3(3), 380-392.

Döğüş, S. (2015). Anadolu'da Hızır-ilyas Kültü ve Hıdrellez Geleneği. Türk Kültürü ve Hacı Bektaş Veli Araştırma Dergisi, (74), 77-100.

Ekici, M. (2016). Türk Kültüründe "Al” Renk. Türk Dünyası İncelemeleri Dergisi, 16(2), 103-107.

Ergun, P. (2010). Türk Gelininin Mitolojik Göçü. Balıkesir Üniversitesi Sosyal Bilimler Enstitüsü Dergisi, 13(24), 275-290.

Eroğlu, A. (2006). Türk Halk Inançlarının Güncel Değeri. I. Türkiyat Araştırmaları Sempozyumu Bildirileri. Ankara: Hacettepe Üniversitesi Türkiyat Araştırmaları Enstitüsü, 87-97.

Günay, U. (1993). Ritüeller ve Hıdrellez. Millî Folklor, (26), 2-3.

Gündüz, Ş. (2007). Nevruz. Türkiye Diyanet Vakfı İlâm Ansiklopedisi içinde. (Cilt 33, s. 60-61).

İbrahimsoylu, i. (2021). Yörüklük (Kuzey Makedonya Yörüklügü). Üsküp: Yeni Balkan.

İnalcık, H., Manisalı, E., Koloğlu, O. (1993). Balkanlar. İstanbul: Orta Doğu ve Balkan İncelemeleri Vakfı.

Kahraman, N., Arıkan, R. (2015). Orta Asya'dan Bilecik'e Hıdrellez. Türk Dünyası Incelemeleri Dergisi, 15(1), 13-28.

Kalafat, Y. (1999). Türk Dünyası Tarih Çalışmalarında Halk İnançlarının Önemi. Millî Folklor, (44), 88-90.

Ocak, A. (1998). Hıdrellez. Türkiye Diyanet Vakfı İslâm Ansiklopedisi içinde. (Cilt 17, s. 313-315).

Oktay, A. (2018). Makedonya Türk Ağızları: Geçmişi ve Bugünkü Durumu. Ulakbilge, 6(29), 1463-1482.

Ögel, B. (1971). Türk Kültürünün Gelişim Çağları. Ankara: Millî Eğitim 
Bakanlığı.

Özkan, i. (2020). Bulgaristan Türklerinde Nevruz ve Hıdrellez Kutlamaları. Balkanlarda Türk Dili ve Edebiyatı Araştırmaları, 2(1), 1-24.

Roux, J. (2011). Eski Türk Mitolojisi. Ankara: Bilgesu.

Sezen, L. (1995). Türk Folklorunda Hıdrellez. Millî Folklor, 1(31), 32-34.

Sezen, L. (1999). İlkyaz Bayramları. Atatürk Üniversitesi Türkiyat Araştırmaları Enstitüsü Dergisi, (12), 81-86.

Şengül, A. (2008). Türk Kültüründe Nevruz ve Anadolu'da Nevruz Kutlamaları. Türk Dünyası Dili ve Edebiyatı Dergisi, (26), 61-73.

Uğurlu, S. (2015). Makedonya-Valandova Hıdrellez Âdetlerinden "Yeşillenme", "Kısmet Kapama" ve "Martufal Çekme" Âdetleri. Türk Uluslararası Dil, Edebiyat ve Halkbilimi Araştırmaları Dergisi, (5), 3760.

Yüce, N. (2011). Hıdrellez Bayramıyla İlgili Bazı Notlar. Türk Dili ve Edebiyatı Dergisi, 44(44), 251-256.

\section{Sözlü Kaynaklar}

Kaynak Kişi: 1

Adı Soyadı: Atice Destanova, 68 yaşında. Ustrumca şehrine bağlı Yüksek Mahalle Köyü.

Kaynak Kişi: 2

Adı Soyadı: Atice Aliova, 59 yaşında. Radoviş şehrine bağlı Alikoç Köyü. Kaynak Kişi: 3

Adı Soyadı: Ayşe Destanova, 62 yaşında. Ustrumca şehrine bağlı Yüksek Mahalle Köyü.

Kaynak Kişi: 4

Adı Soyadı: Cevri Recepova, 74 yaşında. Ustrumca şehrine bağlı Yüksek Mahalle Köyü.

Kaynak Kişi: 5 
Adı Soyadı: Dizar Bekirova, 60 yaşında. Ustrumca şehrine bağlı Yüksek Mahalle Köyü.

Kaynak Kişi: 6

Adı Soyadı: İsmail Yusin, 55 yaşında. İştip şehrine bağlı Radanya Köyü öğretmeni.

Kaynak Kişi: 7

Adı Soyadı: Kerime Şerifova, 64 yaşında. Radoviş şehrine bağlı Kılavuzlu Köyü.

Kaynak Kişi: 8

Adı Soyadı: Kevser İsinova, 36 yaşında. Ustrumca şehrine bağlı Yüksek Mahalle Köyü.

Kaynak Kişi: 9

Adı Soyadı: Nasuf Destanov, 66 yaşında. Ustrumca şehrine bağlı Yüksek Mahalle Köyü imamı.

Kaynak Kişi: 10

Adı Soyadı: Ramize Amedova, 38 yaşında. Radoviş şehrine bağlı Kılavuzlu Köyü.

Kaynak Kişi: 11

Adı Soyadı: Saliye Hüseyin, 52 yaşında. İştip şehrine bağlı Radanya Köyü. 